\title{
An Integrated Model of Collaborative Knowledge Building
}

\section{Gurparkash Singh, Louise Hawkins, and Greg Whymark School of Management and Information Systems Central Queensland University, Rockhampton, Australia}

\section{g.singh@cqu.edu.au, l.hawkins@cqu.edu.au, g.whymark@cqu.edu.au}

\begin{abstract}
This paper describes a model for studying collaborative knowledge building (CKB) as a group activity. We integrate the model described by Stahl (2000a) with an analysis based on the principles of cultural historical activity theory (CHAT), using the analysis of a self reflective case study to guide the description. The concept of the CKB activity system is developed, and the role of contradictions in CHAT is described. The case is then analyzed to show how the model explains collaboration in practice. The final model includes two additional cycles representing the role of reflective practice in CKB. The new model of CKB processes combined with the concept of the activity as the unit of analysis and the tools of CHAT provides an efficacious way of investigating collaborative knowledge building.
\end{abstract}

Keywords: collaboration, knowledge building, reflective thinking, activity theory, zone of proximal development

\section{Introduction}

Current studies in collaborative knowledge building (CKB) concentrate on the processes involved in group of participant's coming together to learn and create knowledge. The focus has gradually shifted from analysing learning outcomes (Lipponen, Hakkarainen, \& Paavola, 2004) and studying effective conditions for collaborative learning (CL) to understanding the processes involved (Dillenbourg, Baker, Blaye, \& O'Malley, 1996). There is a lack of explanation and a cohesive theory regarding the underlying processes involved in CKB. Based on the evidence from our own constructivist teaching strategies and current literature on CKB, we present an initial study undertaken as part of investigating and documenting the CKB process. The study also explores the role of reflective thinking and collaborative reflective discourse in helping participants achieve shared understanding as part of the CKB process. The analysis adds to the existing body of knowledge relating to learning objects within the specific domain of collaboration of learners as identified in the life cycle of the e-learning process (Convertini, Albanese, Marengo, Marengo, \& Scalera,

2006).

Material published as part of this publication, either on-line or in print, is copyrighted by the Informing Science Institute. Permission to make digital or paper copy of part or all of these works for personal or classroom use is granted without fee provided that the copies are not made or distributed for profit or commercial advantage AND that copies 1) bear this notice in full and 2) give the full citation on the first page. It is permissible to abstract these works so long as credit is given. To copy in all other cases or to republish or to post on a server or to redistribute to lists requires specific permission and payment of a fee. Contact Publisher@InformingScience.org to request redistribution permission.
The concept of CKB was introduced by Scardamalia and Bereiter (1994) in their study of learning at school, in which they proposed that schools should function as knowledge building communities. Knowledge building refers to collective work for the advancement and elaboration of conceptual artefacts (Paavola, Lipponen, \& Hakkarainen, 
2002). This knowledge building approach and knowledge building process aims at facilitating collaborative work for sharing and advancing knowledge and artefacts (Scardamalia \& Bereiter, 1994). CKB is conceptualized as a social process in which participants co-construct knowledge through social interactions (Lipponen, 2002; Stahl, 2000a).

Though there are studies documenting CKB (Campos, 2004; Scardamalia \& Bereiter, 1994), exploring the distributed nature of knowledge building in the collaborative context (Aalst, Kamimura, \& Chan, 2005), identifying conditions necessary to support knowledge building communities (Gilbert \& Driscoll, 2002) and identifying knowledge building indicators (Lipponen, 2000), disagreement still exists regarding the nature and process of CKB. It is not yet clear as to how participants develop shared understanding, the nature of interactions involved in $\mathrm{CKB}$ or how conceptual change is brought about in the $\mathrm{CKB}$ process. There are a range of views explaining the development of shared understanding including group cognition (Stahl, 2006), grounding (Baker et al, 1999, as cited in Stahl, 2006), contribution theory (Clark \& Brennan, 1999, as cited in Stahl, 2006) and intersubjective understanding (Yukawa, 2006).

The process of $\mathrm{CKB}$ and the sub-activity of achieving shared understanding moves through constant breakdowns in meaning making between the participants. The participants interpret meaning and develop shared understanding by constantly interacting with each other using language and jointly constructed artefacts. The case study presented here further explores the use of reflective thinking and collaborative reflective discourse as mediating tools for achieving shared understanding and articulating tacit knowledge as part of the CKB process.

Collaborative reflective social discourse serves to make one's experience and viewpoint visible to peers for the purpose of getting a different perspective. Lin, Hmelo, Kinzer, \& Secules (1999) highlight three benefits for reflective social discourse: (a) increased interaction between participants, (b) reflection is more motivating when there is a public audience, and (c) reflection helps ideas and thoughts to become artefacts or objects for further reflection. Yukawa (2006) in his study of online group action learning provided evidence of the potential of collaborative reflection as a core process in group learning.

Viewed from an Informing Science framework the paper analyses how a group of participants construct knowledge and how technology-enabled group activities can be designed to support problem based learning (Cohen \& Nycz, 2006). The paper develops a theoretical and conceptual model for CKB process by modifying Stahl's (2000a) model of CKB, pedagogy of reflective thinking (Herrington \& Oliver, 2002; Rodgers, 2002), and uses constructs of cultural historical activity theory (CHAT) (Engestrom, 2001) for analysing the data. The theoretical support for Stahl's CKB model, apart from other perspectives, focuses on group and personal perspectives, learning and knowledge building being mediated by physical and symbolic artefacts , and internalisation of cognitive artefacts (Stahl, 2002). These perspectives are consistent with the basic constructs of CHAT.

CHAT is compatible with $\mathrm{CKB}$, as they both take as their unit of analysis the group. In order to reach a shared understanding, the group must work through a number of breakdowns, as individuals present and explain their meaning and others question these meanings. Within CHAT, breakdowns are referred to as contradictions, which are defined as "historically accumulating structural tensions within and between activity systems and are not the same as problems or conflicts" (Engestrom, 2001, p137). Identification of contradictions within a dialogue provides the researcher with a method of showing how the contradictions transform the activity. Transformation of the activity leads to a more culturally advanced activity.

The research questions being examined are: 
- What is the role of collaborative reflective discourse in a collaborative knowledge building process?

- What is the relation between reflective thinking and collaborative reflective discourse in the context of CKB?

The next section provides an introduction to CKB and discusses the underlying theory informing its practice. It also provides a rationale for studying and promoting reflective thinking as part of CKB process. The section on unit of analysis discusses the constructs of CHAT that are helpful in analysing the process of CKB. This leads to the section on the case study that provides a background to the case examined and conceptualises CKB as an activity system.

The section on data analysis is divided into three phases. Phase 1 analyzes the use of reflective thinking as a tool for articulating knowledge and discusses the role of individual reflective thinking for articulating tacit knowledge, the role of reflective conceptual artefacts and the use of reflective thinking as a tool mediating the activity. Phase 2 describes the participants engaging in collaborative reflective discourse and achieving shared understanding about the sub-process of developing categories. In Phase 3 the participants use the outcome from the previous activity (shared understanding) to collaboratively build knowledge. Based on historically sequencing the transformations in the CKB activity system, phase 3 presents an integrated model of CKB.

\section{Role of Reflective Thinking in CKB}

Stahl (2000a) in his study of CKB breaks down the process into a number of important phases including cycles of personal understanding and social knowledge building. His model for the CKB process stresses the need to focus on group activities and notes the importance of conceptual artefacts. According to Stahl (2001) CKB is a process of communication where groups of people construct new knowledge through interaction of their ideas and perspectives and is preserved in artefacts (conceptual or written documents). The CKB process, or the way knowledge is built and shared is described as a "synergistic moment" (Stahl, 2000b) by which the group reaches a shared understanding by participating in the socio-cultural process (Stahl, 2001). Each member of the group brings their personal perspective and interpretations of experiences. The process by which a group reaches shared understanding and inter-subjectivity through constant interactions is broken down into smaller knowledge building activities within Stahl's model.

The genesis of new knowledge constructed jointly by participants in a collaborative environment can be explained by the knowledge creation metaphor of learning (a pedagogical approach) (Paavola et al., 2002) and the collaborative knowledge building model (pedagogical model) (Scardamalia \& Bereiter, 1994; Stahl, 2000a). The knowledge creation metaphor provides for a theoretical base by which the CKB model can be understood, applied and explained. Knowledge building involves production and continual improvement of ideas which are of value to a community (Scardamalia \& Bereiter, 1994). Within a community the ideas can be considered as conceptual artefacts that can be examined and improved on by means of public discourse. The knowledge creation metaphor of learning conceptualises knowledge advancement and learning as a collaborative process for developing shared objects of activity which can only be accomplished by participating in cultural practices and by becoming members of knowledge communities (Paavola et al., 2002). Conceptualising CKB as a social process suggests the examination of the process as an activity system (using CHAT), which will be discussed later in this paper. But the question or the problem that needs attention is how participants develop shared understanding and are able to co-create knowledge. Documenting these underlying processes may help in the design of possible technological scaffolds to support the process of CKB.

Aalst and Hill (2006) propose self monitoring of knowledge as an important characteristic and capability that needs to be promoted to develop support for participants in CKB processes. Self- 
monitoring involves a meta-cognitive understanding and an insight into one's own learning process. Engaging in reflective thinking can be a useful way of explicating tacit knowledge (Tillema \& Van der Westhuizen, 2006), internalizing newly acquired knowledge (Kim \& Lee, 2002), and facilitating knowledge construction (Andrusyszyn \& Davie, 1997). Many researchers (Baker \& Lund, 1997; Mayer, 1991, as cited in Y. Kim, 2005; Tishman, Jay, \& Perkins, 1993, as cited Y. Kim, 2005) have identified that reflective thinking (meta-cognition) is an important capability that needs to be cultivated in learning and knowledge building situations. For the purpose of this paper, reflective thinking is described as an active thinking process for monitoring one's own learning process to bring about effective conceptual change. The premise being investigated is the notion of reflective thinking and collaborative reflective discourse being used as mediating tools in the CKB process. The understanding of these underlying processes would help in documenting the process of $\mathrm{CKB}$ and developing a theoretical model to explain the process.

Having established the rationale for examining the role of reflective thinking and collaborative reflective discourse within $\mathrm{CKB}$, the next section presents a background to the case study.

\section{The Case Study}

This is not a traditional empirical case study. The data comes from a recorded collaborative problem solving session (one of many), where the objective was to design teaching material and strategies to achieve certain educational objectives. It happened to be recorded for the benefit of the teaching staff member who had to implement the outcomes. As the session used a product called ZingThing ${ }^{\text {TM }}$ (hereafter called Zing) to facilitate brainstorming and other collaborative activities, much of the output was recorded within the product and was available after the session. The participants included the authors to this paper. The case study could also be presented as an example of reflective self assessment of teaching practices.

However, after the event it became apparent that the session, serendipitously recorded in all detail, could also serve as a tool in another concurrent task which involved research into CKB processes (Singh \& Whymark, 2006). Thus the collaborative session described here is a truly an authentic task, and as such is an ideal vehicle for the purposes of this paper. The conflict of the authors conducting the analysis also being involved in the case is acknowledged, but we believe this has had no affect on the analysis. One limitation is that the participants held known viewpoints on collaboration and participatory knowledge building, but we do not believe this impedes the purpose of this paper.

The physical circumstances of the case are now described. The phenomenon under investigation is the role of collaborative reflective discourse in the CKB process. The context is a group of participants working together in a joint activity to design tutorial activity for a post graduate course. The group participants (P1, P2 \& P3) are part of a teaching faculty and research group focusing on knowledge management and group activities. Participant $1(\mathrm{P} 1)$ is an associate lecturer with research interest in Computer Supported Collaborative Learning (CSCL). CSCL is "a field of study concerned with meaning and practices of joint meaning making and the ways these practices are mediated through designed artefacts (Koschmann, 2002, as cited in Stahl, 2003, p. 523). Participant 2 (P2) is an associate professor with years of experience in research associated with knowledge management and Participant 3 (P3) is a lecturer with research focusing on facilitation of groups.

The tutorial activity being considered by $\mathrm{P} 1, \mathrm{P} 2$, and $\mathrm{P} 3$, involves students using Zing groupware to discuss course concepts and is based on the pedagogy of CL and reflective thinking. The activity involves students brainstorming on a particular theoretical concept selected from the course and listing as many ideas as possible using Zing. During the evaluation phase, each idea is presented to the group for analysis and discussion. Students then need to as a group identify catego- 
ries emerging from the ideas and develop a summary statement of the category explaining the concept. The tutorial activity is based on the principles of social constructivism (Bonk \& Cunningham, 1998), which involves students being responsible for their own learning, multiple perspectives being discussed, knowledge construction, collaboration, and authentic problem solving.

The data was gathered by digitally recording the face-to-face interactions of the participants, via observation and from the interaction report generated by Zing groupware. Analysing a group discussion helps in operationalizing the concepts of CKB process and collaborative reflective discourse.

\section{Unit of Analysis}

CHAT is a descriptive theory of human thought and behaviour within the context of a specific activity. This theory suggests that learning and knowledge building needs to be considered as an activity system that involves subjects and mediating artefacts (cognitive, physical) that act to transform particular objects of activity to achieve an outcome. Activity theory offers a framework for describing the activity, as well as provides a set of perspectives on practice that interlink the individual and the social (Engestrom, 2001). Activity theory as a tool has been used by researchers in studying a wide range of activities, including human computer interaction (Kuutti, 1996), developing computer supported co-operative work tools (Kuutti \& Arvonen, 1992), and analyzing innovative learning in work teams (Engestrom, 1999b). Activity theory is used in this study as a descriptive and an analytical tool that helps in analyzing the group interactions. Learning and knowledge building in CHAT is seen as a situated and social activity interlinking the individual and group level (Nardi, 1996, as cited in Johri, 2005).

\section{The CKB Activity System}

The language provided by activity theory allows for providing rich description of the CKB activity, sub-activity of developing shared understanding and conceptualising CKB as an activity system. According to Engestrom (1987, as cited in Kaptelinin, 2005) the object of the activity is related to production or what is being transformed into the outcome. The object of the activity in this case is concerned with the designing of a tutorial activity by the group.

Figure 1 shows the intersection of the two activities of $\mathrm{P} 1$ and $\mathrm{P} 2 / \mathrm{P} 3$, along with the shared vision of the possible future tutorial activity. The object of the activity for subject $\mathrm{P} 1$ is to present a tutorial activity to the group. The object for $\mathrm{P} 2$ and $\mathrm{P} 3$ is to assess and refine the tutorial activity interactively with $\mathrm{P} 1$. Characteristics common to the two activities of $\mathrm{P} 1$ and $\mathrm{P} 2 / \mathrm{P} 3$ are shown in the triangle at the top of Figure 1. The tutorial activity is designed based on the pedagogy of reflective thinking and principles of social constructivism (Bonk \& Cunningham, 1998). The collective activity of the group is driven by a communal object (Figure 1, intersection of P1, P2, and P3's activity) of designing purposeful and interactive tutorial activity (Engestrom, 1999a). Identifying activity systems at different levels of abstraction allows researcher to identify the correct contextual level needed for analysis (Whymark \& Hawkins, 2006). Figure 1 depicts the activity system at a higher level of abstraction. To document the CKB process, the analysis needs to zoom in at the group level as the object under consideration is the group and the tools the group uses to achieve an outcome that is, collaboratively building knowledge. 


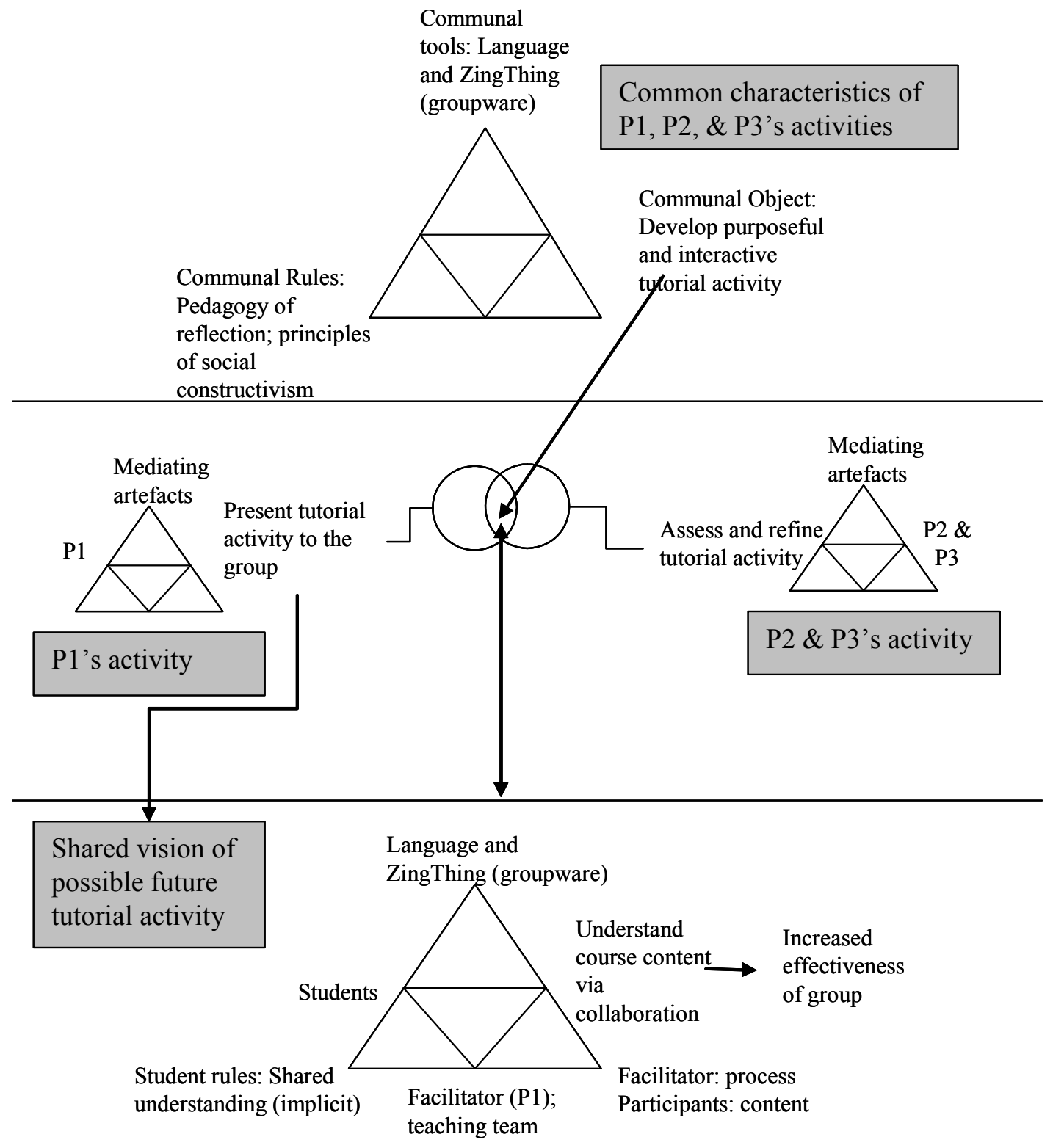

Figure 1: Planning of the tutorial activity

The constructs of CHAT provide a useful and a descriptive framework for analyzing group interactions taking the object oriented activity as a unit for analysis, in this case the designing and planning of a tutorial activity (Engestrom, 1999b). The depth of the descriptions provides insights into the different aspects of the activity being examined helping the researcher to focus on specific aspects, in this case the process and the mediating tools as part of CKB (Whymark \& Hawkins, 2006). The third generation activity theory (Engestrom, 2001) takes interacting activity systems as the unit of analysis that allows the analysis to zoom in and out at the personal and interpersonal planes (Rogoff, 1995). In other words it allows the researcher to focus the analysis at the individual and the group level. 


\section{Contradictions Driving Collaboration}

Language has been described as the tool of tools (Vygotsky, 1978), as it is a tool that once mastered allows individuals to communicate with each other regarding issues in the past, present, and future as well as the discussion of virtual conceptual entities. Language also allows an individual to engage in intrapsychological conversation, as language is used by an individual to 'talk to themselves'.

Within a conversation, contradictions in understanding are constantly being identified and resolved as individuals work together to reach a shared understanding of the topic under discussion. Contradictions are "historically accumulating structural tensions within and between activity systems" (Engestrom, 2001, p137). Contradictions need not be seen negatively but as "driving forces" and opportunities transforming the activities (Whymark \& Hawkins, 2006). "To develop means to resolve or transform these contradictions (instead of merely shifting them elsewhere)" (Nelson \& Kim, 2001, p.4), and it is this change in the activity system that we identify within the data. In order for transformation to a culturally advanced activity to occur, the individuals involved need to be able to openly critique each other's contributions and reflect on their own understanding.

When the activity being undertaken involves reaching a shared understanding of a future proposed activity, dialogue allows for the consideration of how different decisions could potentially impact the achievement of the object of the proposed activity (Hawkins \& Whymark, 2005). Identification of "contradictions seem to be a natural medium for mediating the connection between descriptions of (current) work and requirements on a new formulation of that work" (Turner \& Turner, 2001, p.2), which in turn, increases the participant's shared understanding.

CHAT is used here to explain what happened in the group dialogue, and to show how the activity under investigation was transformed as contradictions were raised and resolved within the collaborative environment.

\section{Data Analysis}

The data analysis began by considering and reconsidering the data and identifying object oriented activities (Yamagata-Lynch, 2003). The object of the activity is related to transformation or production into an outcome (Kaptelinin, 2005). Taking this approach allowed for historically sequencing the process of CKB in the described activity system. The unit of analysis for this study is the interacting activity systems shown in Figure 1. The data analysis described in the following section began by tracing the progression, transformation and expansion of the object oriented activities within the CKB activity system (Figure 1). The activity analyzed here is part of a wider activity system of teaching and research as shown in Figure 1.

The next step involved identifying the contradictions or attempts by participants to repair misunderstandings for developing shared understanding (Stahl, 2006). Stahl describes the repair as a form of socially shared group cognition that takes place through discourse (social interactions, gestures, pose etc.).

The analysis uses CHAT diagrams to document and show the transformations in the activity system. The diagrams help in historically sequencing the transformations in the activity system through different phases with each subsequent phase building on the previous one. Methodologically the study: (a) is purposeful and focuses on understanding and improving teaching practice,

(b) is carried out in close collaboration with practitioners, (c) documents transformations, and (d) is guided by an awareness of a potential to develop a theoretical model of CKB process

(Lipponen et al., 2004). 


\section{Phase 1- Reflective Thinking and Externalisation}

The activity progressed with P1 describing (by showing on the Zing groupware) the processes involved in the tutorial activity. The statements in brackets denote actions taken by participants, within inverted commas are statements entered to or from Zing, the dots (.....) denote small pauses in narration, and the numbers in brackets () next to statement by P1, P2 and P3 denote statement number. They are referred to within the explanations for cross reference.

P1 (1): What we have over here is a group activity which the group engages in every two weeks using ZingThing. What they will be discussing over here will be, they choose a concept which is problematic and if they are not able to choose themselves, I will choose the concept. So the way it goes is.....

Today we will discuss what knowledge is so it is the focus and the agenda is we all have to list what we mean by knowledge. Couple of ideas are already put it in...so if you want you can put in couple of more ideas......and then we can go to the next step...

An initial contradiction in shared meaning occurred when P2 suggested that:

P2 (2): we will talk to you later about writing questions (looking at screen showing questions)

Although this initial breakdown in the activity was not discussed at length immediately, the quote (2) itself is an illustration of P2 using reflection-in-action based on expertise and experience and articulating tacit knowledge. Reflection-in-action refers to active thinking over an ongoing activity to understand and analyze the situation (Kim \& Lee, 2002). It involves carefully examining the current situation by contrasting and comparing it with past experiences and tacit knowledge. By actively evaluating past experiences in context of the ongoing activity $\mathrm{P} 2$ is able to articulate tacit knowledge.

This led to the development of a reflective conceptual artefact as a conceptual representation in the form of "writing questions" by the group participants. Bereiter (2002) defines conceptual artefacts as products or objects of thinking and reasoning that can be collectively argued about. This denotes development of common terminology and participants understanding of what "writing questions" meant in context of the activity. Therefore, the reflective conceptual artefact can be

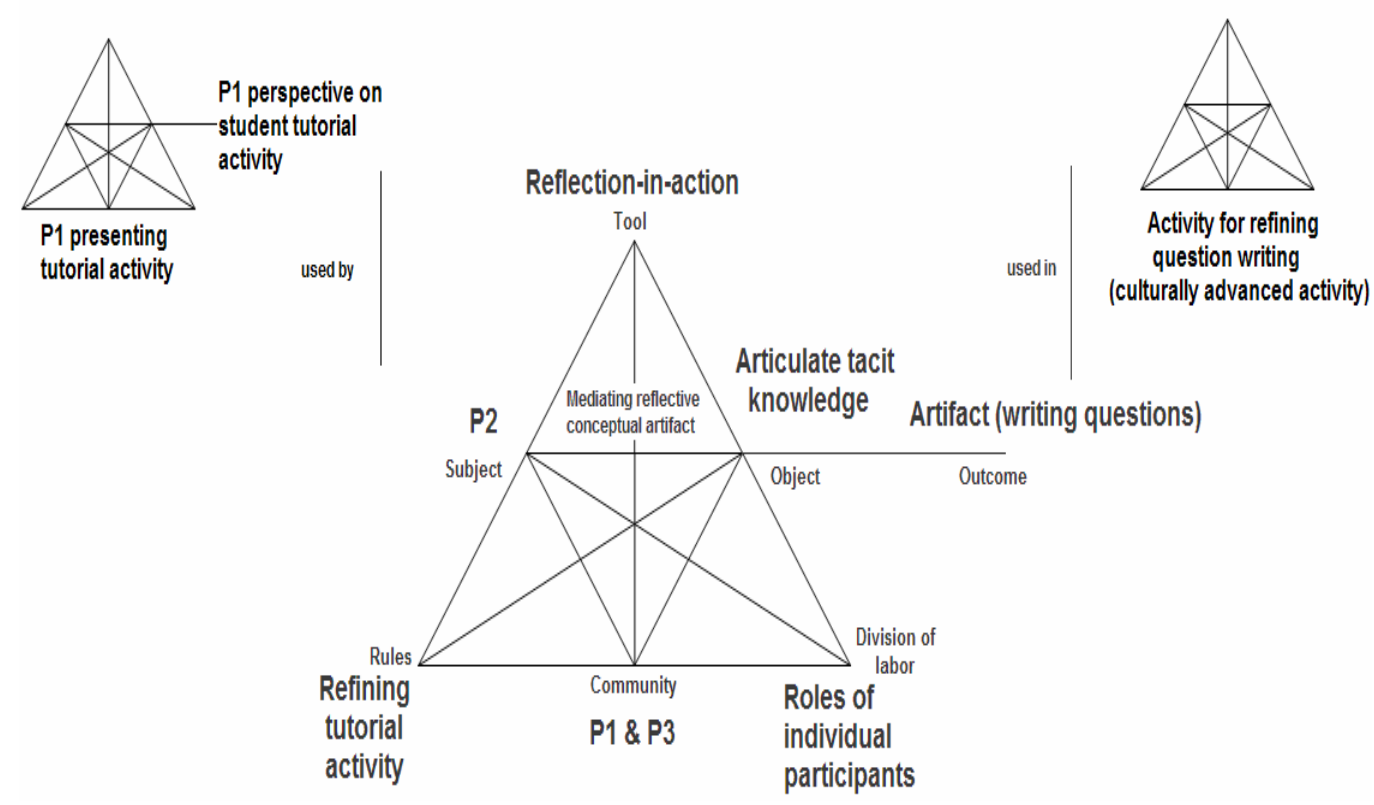

Figure 2: Developing reflective conceptual artefact 
defined as a metaphor explaining the development of an artefact by engaging in and using reflective thinking as a tool in the activity (Figure 2).

The process for developing reflective conceptual artefacts can also be explained by participants appropriating experiences and beliefs on an internal plane as a representational activity (Internalization) (John-Steiner \& Mahn, 1996). These internalized reflective conceptual artefacts are then transformed or externalized (through communicative language, symbols etc) by the participants for $\mathrm{CKB}$, the entire process being mediated by reflective thinking.

Reflective thinking is used as a tool to develop the artefact by P2 and it is then internalized by the group. The internalized artefact was externalized by $\mathrm{P} 1$ based on the common language and terminology developed by the group. It shows the importance of reflective thinking and reflective conceptual artefacts as mediators of developing shared understanding and articulating knowledge at the individual and group level. It also shows the mediating nature of reflective conceptual artefacts in the process of CKB in terms of being used as a tool to transform the activity. The development of the artefact transformed and expanded the activity in terms of P1 merely explaining the tutorial activity to $\mathrm{P} 2$ and $\mathrm{P} 3$ refining and developing a shared understanding of the tutorial activity (Figure 2).

The process constitutes transformation of the artefact and social activity into the inner plane and it is then externalized using common language developed by the group. This is illustrated by the interaction ( $3 \& 4)$ that took place later in the activity where P1 (4) knew what P2 (3) is referring to.

P2 (3): Then asking people to pull out one theme at a time. To me the whole beauty is that you can dream up these thinking paths that make it easier for the participants to answer the question. Like I was going to talk to you about how to write.....questions

P1 (4): Questions (speaking at the same time as P2)

P2 (5): you need fat questions and not thin questions. Fat questions elicit response very easily so rather than, "list what you mean by knowledge" it is simply "what is knowledge". List as many different ideas as you can....so it's more of a action oriented statement...rather than list coming first, its what is knowledge......focus of it is what is knowledge....not discussion on...things like that....

\section{Phase 2- Collaborative Reflective Discourse}

The next contradiction in the progression of the group activity occurred when P1 (6) explained the sub-process of identifying categories from the list of ideas generated as part of the student tutorial activity. The contradiction involved group participants not having a shared understanding of the process of the tutorial activity. It also involved P2 and P3 objective of refining the tutorial activity. It is in the form of a question by P2 (7).

P1 (6): Now what we do after each student has put in their ideas.....we try and develop some common themes in each of these categories.... (Asking question) - What is common within these ideas... and we try and put in themes....so....

P2 (7): How does this theme thing works....just time out your process...can you put in more than one theme or not?

The object of this sub-activity evolves into developing a shared understanding and refining the particular process in the tutorial activity. It shows the expansive and progressive (Aalst \& Hill, 2006) nature of collaborative knowledge building activity whereby the object of the activity evolves and expands (Engestrom, 2001), in this case into developing a shared understanding and the explicit description of sub-processes involved in the student tutorial activity.

The tool used by the group to solve the contradiction and develop shared understanding is collaborative reflective discourse whereby each participant is presenting their own personal perspectives, clarifying, questioning each other's understanding, presenting reasoning for their argument, 
developing a shared understanding, and finally building knowledge through discourse. This subactivity is illustrated by the discourse following the question posed by P2 (7).

Collaborative reflective discourse involves firstly, making explicit one's personal viewpoint and perspective and presenting it to the group using language as a tool. P1 $(6,8)$ presents his perspective on how the group of students will develop and converge on categories using the theme tool from a list of ideas generated.

P1 (8): Yes....lets say one of the themes coming out is knowing....action (Types in to show on Zing).......so that becomes one of the themes

P2 \& P3 interpret and analyze the perspective based on their understanding and experiences. In trying to understand the perspective of $\mathrm{P} 1, \mathrm{P} 2(7,9)$ posed a clarifying question and presented his initial analysis and feedback.

P2 (9): But you only do one at a time? The second thing is.....Its always useful to get the participant's to do as much typing.... when you use the themes box...you have to do the typing

At this stage, P1 (9) is not able to understand the usefulness of P2's idea and presents justification and rationale for following the process based on his experience.

The activity progresses by $\mathrm{P} 2$ (10) presenting his idea to the group. The perspective provided by $\mathrm{P} 2$ is in response to $\mathrm{P} 1$ 's initial explanation.

P2 (10): Why not get one the one of the .......I don't use the themes box....so you need take this with a caveat....maybe we can work out how to operate...but, I always find that its rather than say "what are one of the themes"...it means we are going to ignore all the other things and try and pick out one. Whereas if we read through it... but before we read through it...we are told that we are going to pick what the common themes are...and you get each participant to record the theme in their box as you go through it.....so we read through it once and then we go back......and we go though it again...so its about personal understanding...so you get one person (typing)....perhaps with some re-wording...next one is "justified belief"... how does that fit in (asks question)?...... what l' $\mathrm{m}$ doing now.... is am going through and picking up everything and trying to put into groups... lets say P3 is "the knowing action.... being able to do".

So what I am doing is...I try and build up all the themes....now, if you want to capture them as themes all you have to do is run your mouse over it (shows).... and cut and paste it into the theme....or you can just get them to do this old trick and....F9 it.

The discourse here (10) illustrates P2 use of reflective thinking to articulate tacit knowledge. P2 is confronted with a challenging problematic situation and deals with it based on his personal belief and perspective. Then $\mathrm{P} 2$ brings experience into the thinking and problem domain, helping to reframe the thought. Finally, P2 integrates knowledge with the current problem and takes action in the form of a well defined process. In other words the participant is using reflection-in-action as a tool to deal with the problem and articulate knowledge. The process described above also confirms with the literature on the process and characteristics of reflective thinking (Rogers, 2001; Yukawa, 2006).

P2 (11) completes action on his idea and shows how the sub-process of developing themes can be achieved by the students. It is still not clear to P1 (12) how P2 idea works as compared to his personal viewpoint.

P2 (11): now we have 4 themes...you can send them up after the $x x x x x x x x \ldots y o u$ can actually say...... So you put in XXX-THEMES-XXX...l'll show you

P1 (12): what I was thinking was.... I could open up the themes box \& copy all these (shows on Zing)......they are highlighted... we can take it across \& move it to the agenda P2: all right... we will do it that way

P3 (13): You can do it the theme way...but if you highlight...theme no. 17 for example which was F9 up that would put it up to the thing anyway... and double clicking it will become the agenda 
P1 (14): it becomes the agenda

P3 (15): yea...so you don't need to theme it to make it an agenda

P1 (16): ok

It is at this stage through the intervention and action of $\mathrm{P} 3(13,15)$ that $\mathrm{P} 1(14,16)$ begins to understand why his idea of students developing categories using the theme tool would not be as effective as compared to the idea presented by P2 and P3. The discussion also shows the coconstruction of what Yukawa (2006) refers to as representational artefacts. They are in the form of common terminology (themes, agenda, XXX-THEMES-XXX) and participants develop shared understanding by co-creating and interacting with these artefacts at the group level.

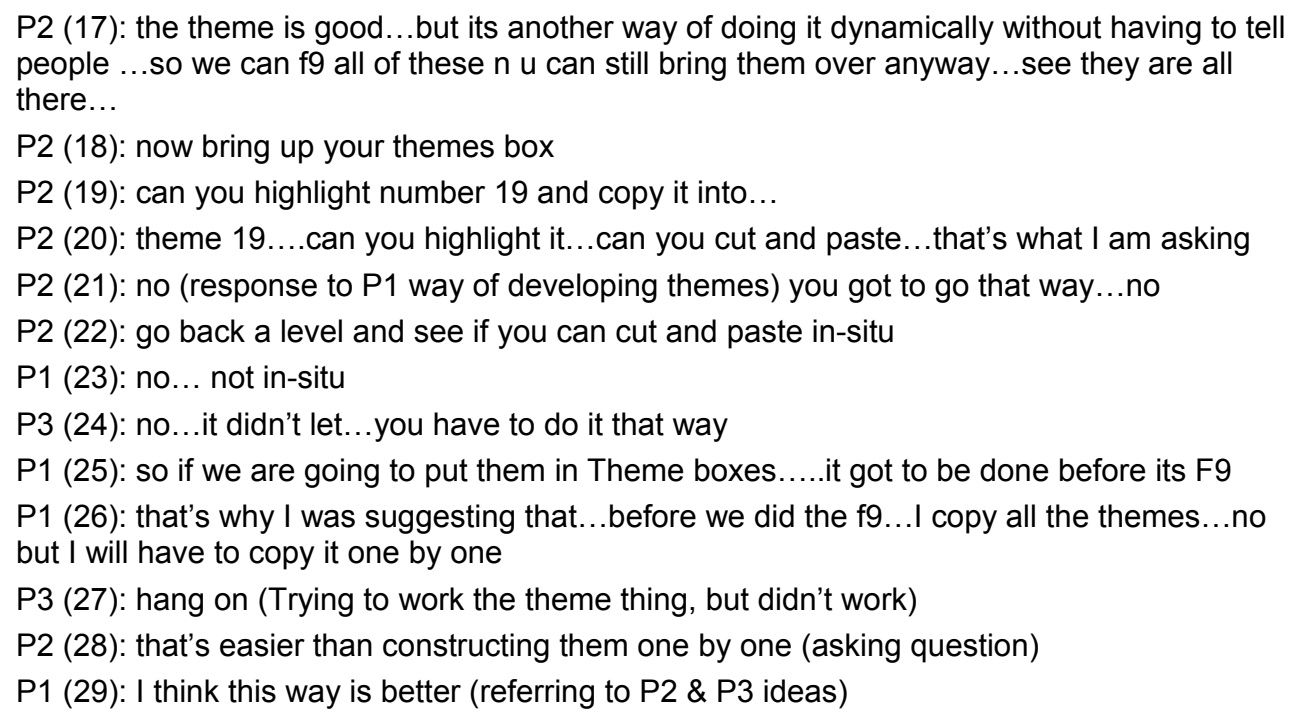

In the discourse from statement 17 to 29 , the participants try to construct the sub-process of developing categories more efficiently by exploring the possibility of using the theme tool. It is through taking action and exploring their beliefs and perspectives that leads to conceptual change and new understanding of the Zing tool and the process of tutorial activity.

The prominent contributions to the practice and literature of reflection and reflective practice have been of Dewey, Boud and Schon (Kim \& Lee, 2002; Yukawa, 2006). Important characteristics of reflective thinking include critical examination of beliefs and experiences, taking action, and affective changes to understanding. In the discourse (20 to 31), the participants are collaboratively working together to develop a process for a tutorial activity. It is through attending to their perspectives, articulating and sharing knowledge with the group, evaluating them by taking action, and getting feedback that the group achieves shared understanding of the process and an effective change in conceptual understanding is brought about. This is illustrated in the response by P1 $(26,29)$ to $\mathrm{P} 2$ question $(28)$.

Yukawa (2006, p. 206) in his study of action learning in groups identified "three interactional characteristics of collaborative reflection: (1) sharing experience, information, and feelings; (2) achieving intersubjective understanding through collaborative meaning making; and (3) synergy between collaborative reflection and relationship building".

Each of these characteristics is present in the discourse discussed here. P2 (10) and P3 (13) use their prior experiences for refining the tutorial activity, participants share experiences with the group, evaluate and reason perspectives, and develop shared understanding by taking action in the current activity. The participants were able to develop shared understanding by interacting with co-created artefacts and interpreting meaning using reflective thinking at the individual level and collaborative reflective discourse at the group level (17 to 29). The outcome of the individual re- 
flective thinking activity (Figure 2), articulated knowledge artefacts (e.g. - writing questions), is used by all participants for developing a shared understanding.

The sub-activity of developing shared understanding and refining the tutorial activity is being mediated by participants using reflective thinking and developing reflective conceptual artefacts for reasoning and discussion. It also brings to the foreground the dynamic relationship between individual reflective activities and the social nature of collaborative reflective discourse with one helping the other. By individually engaging in reflective thinking, participants are able to articulate knowledge, create artefacts for discussion and interpret meaning. Collaborative reflective discourse involves explicitly seeking feedback through social interactions for examining multiple perspectives through reasoning, clarifying, questioning, and weighing reasoning (Yukawa, 2006). In other words, the outcome of individual reflective thinking activity is fed into the wider activity system at the group level for developing shared frames of references and shared understanding. The artefacts created by the group like "build up all the themes" (10) (different from Theme tool), "writing questions" (2), "fat and not thin questions" (5), "XXX-THEMES-XXX" (11), and "F9 it" $(17,26)$ only have meaning when they are understood in context of the activity. They were developed using reflective thinking as a tool at the individual level and collaborative reflective discourse was used as a tool to develop shared understanding at the group level.

It is through engaging in discussions, articulating individual perspectives, questioning of the multiple perspectives, providing feedback, asking clarifying questions, co-creating linguistic artefacts at the group level and interacting with them to develop common terminology that the group was able to develop shared understanding. Alternatively, Yukawa (2006, p. 206) defines this process of collaborative reflective discourse as "a collaborative critical thinking process involving cognitive and affective interactions between two or more individuals who explore their experiences in order to reach new intersubjective understanding". P1's initial understanding of the sub-process of developing categories evolves based on the feedback, discussion and action by the group. Therefore, the group comes to an understanding of developing categories by not using the theme tool provided by the application, instead using collaborative reflective discourse as a tool (Figure 3).
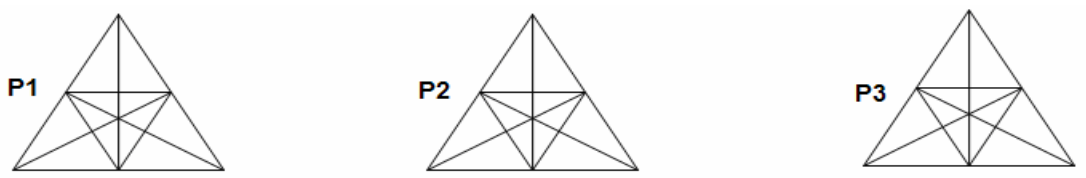

Outcome: Artifacts

Reflective thinking as a tool at individual level

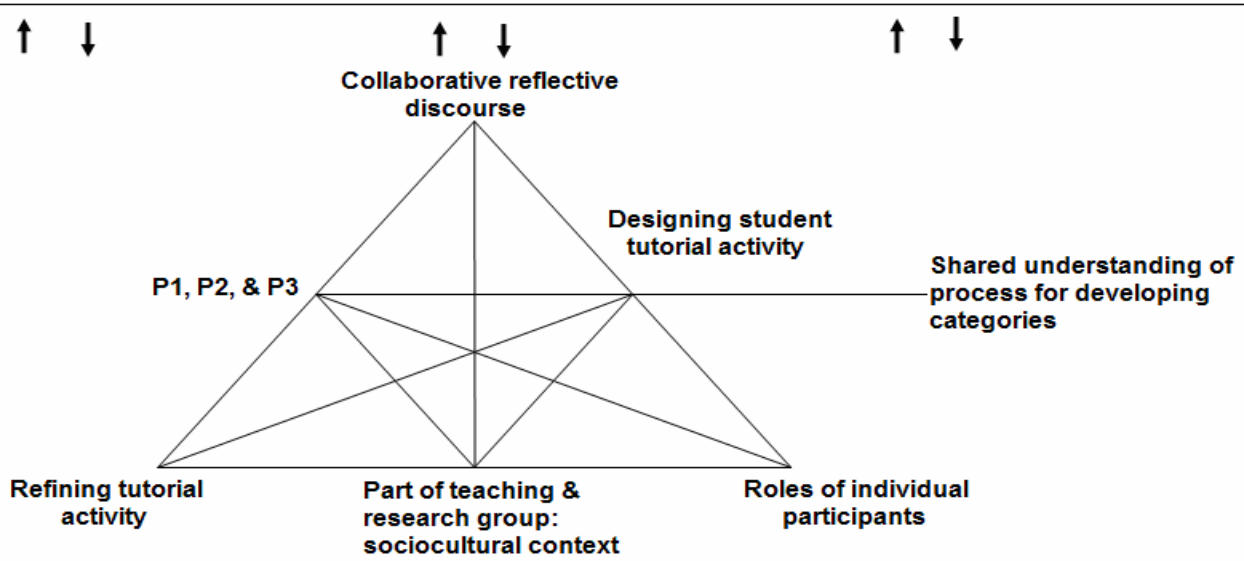

Figure 3: Collaborative reflective discourse as a tool 


\section{Phase 3 - Collaborative Knowledge Building}

The third phase involved the group of participants using their shared understanding to collaboratively build knowledge in the form of artefacts that are of importance and used in other activities (practice and process of student tutorial activity - culturally advanced activity, Figure 1). The emphasis in CKB is on developing shared objects of activity and collaborative advancement of conceptual artefacts (plans, products, theories) (Scardamalia \& Bereiter, 1994). After developing a shared understanding about how to develop categories from a list of ideas (in the discourse it is referred to as themes and is different from the theme tool provided by Zing), the participants discuss how students would develop summary statements explaining each category developed.

The activity progresses with P1 (30) explaining how students would develop summary statements explaining each of the categories (themes). The contradiction in shared meaning occurs with P3's questions (31) regarding the way the process should unfold.

P1 (30): so after developing the themes...we click on one of the themes so that it becomes the agenda, then what they have to is...they have to discuss about it... what they understand about it... and I will also encourage...so say for e.g. I am saying "personal understanding is developing mental models"...I would like you to question it.... as to what do you mean by mental models....all this is being done by putting in your ideas

P3 (31): so do you want them to put in ideas...or do you want to discuss it

P1 (32): I want them to put in ideas and at the same time if they have any doubt discuss it also. So say for example I put in "mental models" and f9 it and I would encourage if there is any other group member doesn't understand what I am saying or know they try and discuss it also... and at the end of it....when all the discussion has been done then using maybe theme or the way P2 does it you develop one common terminology

P3 (33): you could ask them to put in what there ideas are and discuss each one....if you say does anyone does not understand you might not get anyone answering....as if anyone is going to say I don't understand that

P2 (34): it needs to be a positive action rather than a negative action

P1 (35): just coming back to what P3 was saying...discussing and listing ideas on one particular theme...so I should not encourage discussion and listing at same time...they list there ideas and then go onto the discussion

P2 (36): you might need some discussion to get them thinking before they start typing...on the right hand side of the screen...Talk, Type. Read. Review is the protocol...so you talk about it...once ideas start flowing...you say lets capture those ideas on your keyboard...then they read it after they done the brainstorming....and then you review it and that's your discussion

P3 (37): and you might have...like you don't know exactly what the themes are going to be from the first lot...but you know you are going to get themes out because that's what you are going to be asking about ....so are there questions you can pose to the group to talk about for that theme before they do the brainstorming...so you have generic questions you can ask about anything that comes up

P1: (38) so that would stimulate the thinking

The discourse shows the development of a process for creating summary statements. It begins with P1 presenting his idea $(30,32)$, P3 questioning and refining it $(31,33)$, and moves to all three participants working together to create a thinking path $(33,35,36,37)$ for the students. This jointly constructed thinking path shows the co-construction of knowledge by the group that is not attributable to any single participant but to the group as a whole. The participants use co-created artefacts (put in ideas, generic questions, and thinking path) to engage in discussion leading to an effective conceptual change in understanding $(35,38)$. The outcome of the activity at this stage is in the form of a thinking path for students.

P1 (39): after having listed ideas for themes, what I want is discussion...do you actually understand what these ideas mean...just as a group discuss what do u mean by " mental models " 
P3 (40): its maybe now that you have four layers...it maybe that ...you read through them and then you go back up next theme and you go and do that

P2 (41): this would be a good spot for the theme (referring to theme tool).......bring your theme up...I really actually love the participants to do the typing....it relieves me from ownership of it...gets them owning it...they can type while I am doing other things

P3 (42): because you are running the process...the typing is content

P2 (43): so how about you get us to develop a single summary statement of it....but don't F9 it $\mathrm{n}$ then you will cut and paste it into a theme...so that's what we will do...so take us through producing a single summary statement

P1 (44): now what we are trying to achieve is we need to combine these 10 ideas into 1 or 2 sentences ... (starts reading ideas on Zing)

P2 (45): no...you said "mental models"... what do you want us to do with that...we going to sit here and listen to you or we engage some collaborative activity reflective activity...if we sit and listen to you...... we are not going to be very reflective

P2 (46): "personal understanding and multiple realities" (reading from ideas on Zing)...does mental model belong in that...in other words we go and evaluate whether themes belong together or not

P1 (47): so you pick out an idea...get out an idea in front of the group and ask them whether it fits in

P2 (48): there is a collaborative assessment of that idea...so it's a collaborative reflective process... (Provides examples by working on 3 ideas)

What you are doing is helping the group in collaborative reflective process...so 4 and 5 (referring to ideas on Zing) ....are they sufficiently answered by what we already got there ,....if no then you get them to add more... but it's the group that's making the decision ...that makes it a collaborative reflective process... not you

This is what facilitator got to do.....prompt the group...reflect on this...does this fit...put it in for a reason... put things in to prompt the discussion ...so in your lecturers...you put things in to bring up discussion (work on Zing to develop summary statement from ideas)

P2 (49): so now can you cut and paste it into a theme (using theme tool)

$\mathrm{P} 1$ (50): so that is one of the themes that has come out (referring to summary statement)

At this stage, P1 presents his idea on the way to develop summary statements (39). P2 and P3 build upon that idea $(40,41)$ and the emergent outcome $(43)$ is in the form of a knowledge artefact and the value of this artefact only comes when it is placed in context of the activity. P2 further adds value to the knowledge artefact (practice and process of student tutorial activity) by providing feedback (45) and an affective conceptual change is shown by P1 (47). Statements 49 and 51 confirm that the group activity has resulted into an outcome, that is, in the form of practice and process for a student tutorial activity. The outcome is emergent in the discourse and not in individual statements by participants.

The discourse presented here shows the creation of a tutorial activity in the form of specific subprocesses based on a thinking path. Based on the principle of CHAT, every human activity is mediated through artefacts (cultural, social, language, conceptual, material). The artefacts in this case are "listed ideas for themes" (39), "combine these 10 ideas" (44), "collaborative assessment" (48), and "prompt the group" (48). It is through interacting with these artefacts that the participants are able to achieve the communal object. Each participant engaged in the activity uses reflective thinking as a tool at the individual level to develop or interpret the meaning of conceptual artefacts, collaborative reflective discourse as a tool at the group level for developing shared understanding of multiple perspectives and, co-create knowledge with the help of mediating artefacts.

The discourse shows the progressive nature of CKB as conceptualised by Aalst and Hill (2006) and Bereiter (2002). The participants have a communal object of designing a tutorial activity. Based on their individual expertise, participants are working towards reinvesting their learning and knowledge into a new problem situation for the advancement of the community's knowledge 
through mutual understanding and discussion. The process is mediated through repairing of contradictions between and among reflective conceptual artefacts using collaborative reflective discourse as a tool. The discourse also illustrates the mediating nature of the knowledge building process (Lipponen et al., 2004). The group activity is concerned with the communal object of developing a tutorial activity and this shared object is what is driving the activity forward and transforming it. By identifying contradictions in shared meaning the participants are working towards developing a shared understanding. In other words, the contradictions are driving and transforming the activity.

The outcome at one level of the activity system (Figure 2) helps transform the activity (Figure 3) showing the expansive nature of CKB. The reflective conceptual artefacts move into the wider activity system for helping in the development of shared understanding. Shared understanding between the participants then expands the CKB activity system to help participants reach an outcome in the form of a practice or tutorial activity for students (Figure 4). The object within CKB activity system moved from a state of situationally given raw material (P1 presenting his tutorial design, (1)) to a collectively constructed shared meaning (P1 understanding of sub-process of developing categories scaffolded by P2 \& P3, (29)) and to a collaboratively constructed shared object of the activity (combined ideas of P1, P2 and P3 resulting in refined tutorial activity, $(40,43$, 47, 48)) (Engestrom, 2001).

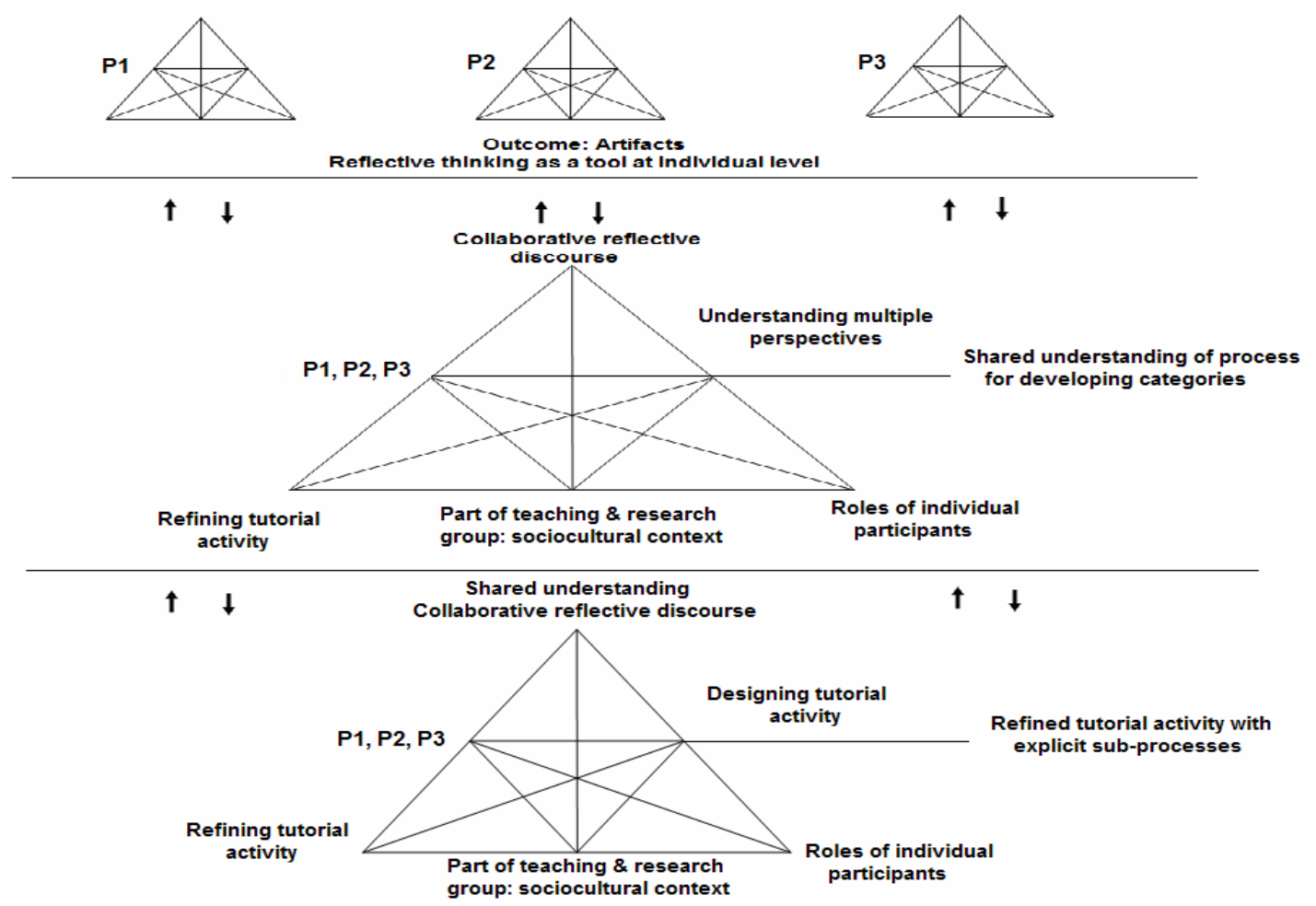

Figure 4: Expanded CKB activity system

\section{The Integrated Model of CKB}

Based on sequentially documenting the process of CKB by analysing the transformations in the CKB activity system and using Stahl's model of CKB (Stahl, 2000a) as a starting point, we present an integrated model of CKB. It would be wrong to assume that the process of CKB always goes through same sequence as shown. $\mathrm{CKB}$ involves a set of complex processes and different 
interacting variables (group size, gender, social environment, nature of task, technology used, language, group composition, and relations) (Dillenbourg, 1999; Dillenbourg et al., 1996). To establish causal links between these variables or to represent the process diagrammatically is almost impossible. The model, however, can be a useful starting point for identifying the processes involved within $\mathrm{CKB}$, understanding those processes, developing a sound theory, and possibly identifying processes for which technological scaffolds can be provided.

The model (Figure 5) includes a cycle of personal understanding that is focusing at the individual level. Cycle 1 shows the use of reflective thinking as a tool at the individual level to develop reflective conceptual artefacts discussed in Phase 1. The reflective conceptual artefacts are used by participants while discussing different perspectives. Tacit pre-understanding represents the individual's use of prior experiences and knowledge. When faced with a problematic situation, an individual uses reflective thinking to articulate tacit knowledge in the form of conceptual artefacts and it is through interacting with these artefacts that individuals interpret meaning, are able to engage in discussions, develop a shared understanding and collaboratively build knowledge.

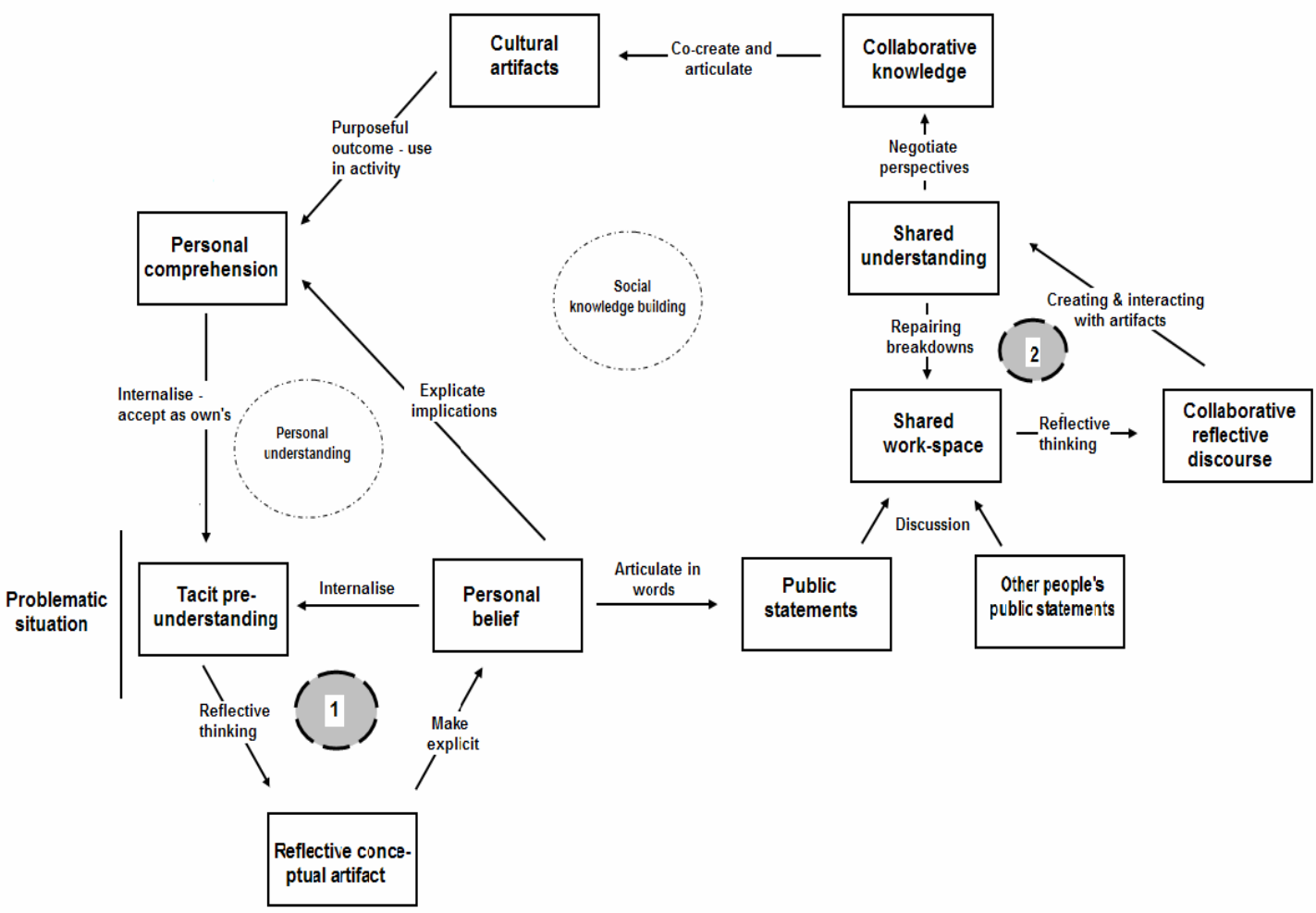

Figure 5: A model of CKB process (Adapted from Stahl, 2000a)

The social knowledge building cycle represents the CKB process at the group level. The shared work-space represents a common medium through which the participants are interacting and could be in the form of a groupware application, message board, or even a face to face discussion. Once the participants have presented their personal perspectives and viewpoints on an issue, the group engages in discussion to develop shared understanding (cycle 2). Shared understanding is important in terms of making sure that each perspective is understood and participants are on some level of common ground. At this stage, collaborative reflective discourse is used as a tool for developing shared understanding. There is also a synergy between individual reflective thinking and collaborative reflective discourse with the former working at the individual level and latter at the group level. Even though cycles 1 and 2 are shown as separable, they are intertwined at 
various levels of abstraction in the CKB process. The cycles are separated in the model to highlight the modification to the original Stahl (2000a) model of CKB. The development of the model is a starting point for developing a cohesive theory for CKB that would serve to provide a framework for designing such environments.

\section{Conclusions}

Social Constructivists maintain the emphasis on social interactions as a precondition for learning and knowledge building (Nyikos \& Hashimoto, 1997). The case study presented here provides an activity theory analysis of group interactions. The constructs, language, and the diagram provided by CHAT helps in analysing the data and zoom in and out at the individual and group level to show the co-creation of knowledge in the form of an outcome.

The discourse listed above shows the creation of knowledge at the group level whereby the knowledge constructed is not attributable to any one participant but to the group. It brings to attention the possibility of a group zone of proximal development (ZPD) (Nyikos \& Hashimoto, 1997 ) explaining the CKB process. ZPD is defined as "distance between the actual development level as determined by independent problem solving and the level of potential development as determined through problem solving under adult guidance or in collaboration with more capable peers" (Vygotsky, 1978, p. 86).

Each participant in the group has an individual ZPD. But through collaborative social interaction each individuals ZPD is extended and intersects at the group level. P2 and P3 based on their experience and expertise helped P1 to come to an understanding of how students can develop categories from a list of ideas. Alternatively, shared understanding and refining of the tutorial activity was only made possible by each participant presenting their perspective to the group, questioning and clarifying, engaging in discussion, and finally re-constructing meaning and the process.

Therefore, collaborative reflective discourse is being used as a tool within this activity for helping individual and group ZPD, as part of the CKB process.

One of the limitations of the study is the nature of the case study data used. However, the purpose of this paper is theory building and no generalization of the case study results is implied. Due to the fact that the case involved the authors in their teaching role, means that this paper has also provided a useful guide to reflective analysis of teaching activities (and of any collaborative exercise) using the activity as the unit of analysis.

Placing this work in context of the studies conducted within the Informing Science framework, the paper addresses the need for designing theory informed and technology-enabled tutorial activities for students (Salas \& Ellis, 2006), encouraging the development of virtual communities of practice (Dube, Bourhis, \& Jacob, 2006), and understanding how collaboration supports knowledge building, which in turn supports the development of learning objects and technical scaffolds (Convertini et al., 2006). The model of the CKB process presented here needs to be further corroborated with data to develop a cohesive theory and model of CKB. Further studies in CKB need to focus on identifying and documenting the underlying processes involved in CKB. The study shows the efficacy of CHAT as an analytical tool, the possible role of reflective thinking and collaborative reflective discourse in $\mathrm{CKB}$, and the possibility of developing a framework for CKB based on which environments can be designed. 


\section{References}

Aalst, J. V., \& Hill, C. M. (2006). Activity theory as a framework for analysing knowledge building. Learning Environments Research, 9, 23-44.

Aalst, J. V., Kamimura, J., \& Chan, C. K. (2005). Exploring collaborative aspects of knowledge building through collaborative summary notes. Paper presented at the International Conference on Computer Supported Collaborative Learning.

Andrusyszyn, M., \& Davie, L. (1997). Facilitating reflection through interactive journal writing in an online graduate course: A qualitative study. Journal of Distance Education, 12(1), 103-126.

Baker, M. J., \& Lund, K. (1997). Promoting reflective interactions in a computer supported collaborative learning environment. Journal of Computer Assisted Learning, 13, 175-193.

Bereiter, C. (2002). Education and mind in the knowledge age. Mahwah: NJ: Lawrence Erlbaum Associates.

Bonk, C., \& Cunningham, D. (1998). Searching for learner-centered, constructivist, and sociocultural components of collaborative educational learning tools. In C. J. Bonk \& K. S. King (Eds.), Electronic collaborators: Learner-centered technologies for literacy, apprenticeship, and discourse (pp. 25-50). Mahwah, NJ: Lawrence Erlbaum Associates.

Campos, M. (2004). A constructivist method for the analysis of networked cognitive communication and assessment of collaborative learning and knowledge building. Journal of Asynchronous Learning Networks, 8(2), 1-29.

Cohen, E. B., \& Nycz, M. (2006). Learning objects: An informing science perspective. Interdisciplinary Journal of Knowledge and Learning Objects, 2, 23-34. Available at http://ijklo.org/Volume2/v2p023034Cohen32.pdf

Convertini, V. C., Albanese, D., Marengo, A., Marengo, V., \& Scalera, M. (2006). The OSEL Taxonomy for the classification of Learning Objects. Interdisciplinary Journal of Knowledge and Learning Objects, 2, 125-138. Available at http://ijklo.org/Volume2/v2p125-138Convertini.pdf

Dillenbourg, P. (1999). What do you mean by 'collaborative learning'? In P. Dillenbourg (Ed.), Collaborative-learning: Cognitive and computational approaches (pp. 1-19). Oxford: Elsevier.

Dillenbourg, P., Baker, M., Blaye, A., \& O'Malley, C. (1996). The evolution of research on collaborative learning. In E. Spada \& P. Reiman (Eds.), Learning in humans and machine: Towards an interdisciplinary learning science (pp. 189-211). Oxford: Elsevir.

Dube, L., Bourhis, A., \& Jacob, R. (2006). Towards a typology of virtual communities of practice. Interdisciplinary Journal of Information, Knowledge, and Management, 1, 69-93. Available at http://ijikm.org/Volume1/IJIKMv1p069-093Dube.pdf

Engestrom, Y. (1999a). Expansive visibilization of work: An activity-theoretical perspective. Computer Supported Cooperative Work, 8, 63-93.

Engestrom, Y. (1999b). Innovative learning in work teams: Analyzing cycles of knowledge creation in practice. In Y. Engestrom, R. Miettinen \& R. Punamaki (Eds.), Perspectives on activity theory: Cambridge University Press.

Engestrom, Y. (2001). Expansive learning at work: Toward an activity theoretical reconceptualization. Journal of Education and Work, 14(1), 133-155.

Gilbert, N. J., \& Driscoll, M. P. (2002). Collaborative knowledge building: A case study. Educational Technology Research and Development, 50(1), 59-79.

Hawkins, L., \& Whymark, G. (2005). Planning for facilitation of virtual meetings: An activity theory based framework. In G. Whymark \& H. Hasan (Eds.), Activity as the focus of information systems research (pp. 5-27). Eveleigh: Knowledge Creation Press. 
Herrington, J., \& Oliver, R. (2002). Designing for reflection in online courses. In A. Goody, J. Herrington $\&$ M. Northcote (Eds.), Research and development in higher education (pp. 313-319). Perth: Higher Education Research and Development.

John-Steiner, V., \& Mahn, H. (1996). Socicultural approaches to learning and development: A Vygotskian framework. Educational Psychologist, 31(3/4), 191-206.

Johri, A. (2005). Online, offline and in-between: Analyzing mediated-action among American and Russian students in a global online class. In T. Roberts (Ed.), Computer supported collaborative learning in higher education (pp. 283-312). London: Idea Group Publishing.

Kaptelinin, V. (2005). The object of the activity: Making sense of the sense-maker. Mind, Culture, and Activity, 12(1), 4-18.

Kim, D., \& Lee, S. (2002). Designing collaborative reflection supporting tools in e-project-based learning environments. Journal of Interactive Learning and Research, 13(4), 375-392.

Kim, Y. (2005). Cultivating reflective thinking: The effects of a reflective thinking tool on learners' learning performance and meta-cognitive awareness in the context of on-line learning. Pennsylvania State University.

Kuutti, K. (1996). Activity theory as a potential framework for human-computer interaction research. In B. A. Nardi (Ed.), Context and consciousness: Activity theory and human computer interaction (pp. 1744). Cambridge, MA: MIT Press.

Kuutti, K., \& Arvonen, T. (1992). Identifying potential CSCW applications by means of activity theory concepts: A case example. Paper presented at the Proceedings of the ACM 1992 Conference on CSCW. Retrieved 29/6/06, from http://delivery.acm.org/10.1145/160000/150955/p233kuutti.pdf?key $1=150955 \&$ key $2=0155151711 \&$ coll $=$ GUIDE $\&$ dl $=$ GUIDE,ACM $\& C F I D=11358728 \& C$ FTOKEN $=25412698$

Lin, X., Hmelo, C., Kinzer, K., \& Secules, T. J. (1999). Designing technology to support reflection. Educational Technology, Research and Development, 47(3), 43.

Lipponen, L. (2000). Towards knowledge building discourse: From facts to explanations in primary students' computer mediated discourse. Learning Environments Research, 3, 179-199.

Lipponen, L. (2002). Exploring foundations for computer-supported collaborative learning. Paper presented at the 4th Computer Support for Collaborative Learning: Foundations for a CSCL Community, (CSCL-2002), Boulder, Colorado.

Lipponen, L., Hakkarainen, K., \& Paavola, S. (2004). Practices and orientations of CSCL. In J. W. Strijbos, P. A. Kirschner \& R. Martens (Eds.), What we know about CSCL and implementing it in higher education (pp. 31-50). Boston: Kluwer Academic.

Nelson, C. P., \& Kim, M. K. (2001, Fall). Contradictions, appropriation, and transformation: An activity theory approach to L2 writing and classroom practices. Paper presented at the Texas Foreign Language Education Conference, University of Texas, Austin.

Nyikos, M., \& Hashimoto, R. (1997). Constructivist theory applied to collaborative learning in teacher education: in search of ZPD. The Modern Language Journal, 81(4), 506-517.

Paavola, S., Lipponen, L., \& Hakkarainen, K. (2002). Epistemological Foundations for CSCL: A Comparison of Three Models of Innovative Knowledge Communities. In G. Stahl (Ed.), Computer supported collaborative learning: Foundations for a CSCL community: Proceedings of the Computer-Supported Collaborative Learning 2002 conference (pp. 24-32). Hillsdale, NJ: Lawrence Erlbaum.

Rodgers, C. (2002). Defining reflection: Another look at John Dewey and reflective thinking. Teachers College Record, 104(4), 842-866.

Rogers, R. (2001). Reflection in higher education: A concept analysis. Innovative Higher Education, 26(1), $37-57$. 
Rogoff, B. (1995). Observing sociocultural activity on three planes: Participatory appropriation, guided participation, and apprenticeship. In J. V. Wertsch, P. Del Rio \& A. Alvarez (Eds.), Sociocultural studies of mind (pp. 139-164). New York: Cambridge University Press.

Salas, K., \& Ellis, L. (2006). The development and implementation of learning objects in a higher education setting. Interdisciplinary Journal of Knowledge and Learning Objects, 2, 1-22. Available at http://ijklo.org/Volume2/v2p001-022deSalas.pdf

Scardamalia, M., \& Bereiter, C. (1994). Computer support for knowledge-building communities. The Journal of the Learning Sciences, 3, 265-283.

Singh, G., \& Whymark, G. (2006). Investigating the support of reflective activities by collaborative technologies: An activity theory based research model. Paper presented at the Transformational Tools for 21st Century Minds.

Stahl, G. (2000a). A model of collaborative knowledge-building. Paper presented at the Proceedings of Fourth International Conference of the Learning Sciences (ICLS 2000), Ann Arbor, MI.

Stahl, G. (2000b). Perspectives on collaborative knowledge-building: Proposal to National Science Foundation program in Information Technology Research.

Stahl, G. (2001). Perspectives on collaboration: A micro-ethnographic study of computational perspectives in computer support for collaborative knowledge-building at a virtual biology laboratory. National Science Foundation program in Computers and Social Systems.

Stahl, G. (2002). Contributions to a theoretical framework for CSCL. Paper presented at the Computer Supported Collaborative Learning (CSCL 2002). Retrieved from http://www.cis.drexel.edu/faculty/gerry/cscl/papers/ch15.htm.

Stahl, G. (2003). Meaning and interpretation in collaboration. In B. Wasson, S. Ludvigsen \& U. Hoppe (Eds.), Designing for change in networked environments (pp. 523-532). Dordrecht: Kluwer Academic Publishers.

Stahl, G. (2006). Group cognition: Computer support for building collaborative knowledge. Cambridge: MA: MIT Press.

Tillema, H., \& Van der Westhuizen, G. J. (2006). Knowledge construction in collaborative enquiry among teachers. Teachers \& Teaching: Theory and Practice, 12(1), 51-67.

Turner, P., \& Turner, S. (2001). Describing team work with activity theory. Cognition, Technology \& Work, 3(3), 127-139.

Vygotsky, L. (1978). Mind and society (Translated by A. Blunden and N. Schmolze). Cambridge, Massachusetts: Harvard University Press. (Original work published 1930.)

Whymark, G., \& Hawkins, L. (2006). Using activity theory to provide rich descriptions of a collaborative learning exercise. In F. Burnstein \& H. Linger (Eds.), The local and global in knowledge management - Why culture matters (pp. 137-149). Kew, Victoria, Australia: Australian Scholarly Publishing.

Yamagata-Lynch, L. C. (2003). Using activity theory as an analytic lens for examining technology professional development in schools. Mind, Culture, and Activity, 10(2), 100-119.

Yukawa, J. (2006). Co-reflection in online learning: Collaborative critical thinking as narrative. International Journal of Computer-Supported Collaborative Learning, 1(2), 203-228. 


\section{Biographies}

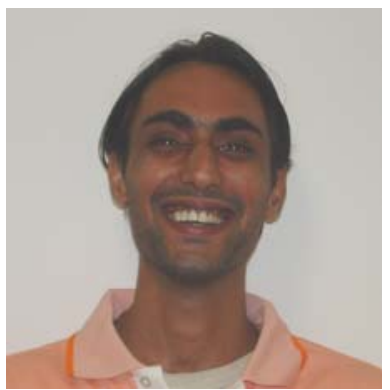

Gurparkash Singh is lecturer and a PhD candidate in the School of Management \& Information Systems at the Faculty of Business and Informatics at Central Queensland University (CQU), Rockhampton, Queensland, Australia. He has completed a graduate diploma in Information Technology (MAHE, Manipal, India) and Masters of Information Systems from CQU. He is part of Group SolutionS Research Group and his research interests include knowledge management, collaboration, collaborative knowledge building, and activity theory.

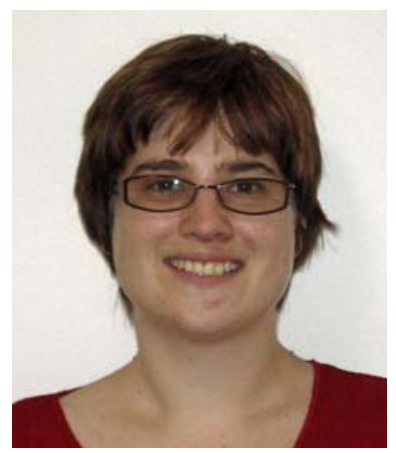

Louise Hawkins is a $\mathrm{PhD}$ candidate and academic with the Faculty of Business and Informatics, Central Queensland University. Ms Hawkins is a member of the Group SolutionS research group at CQU, has published in areas including Activity Theory and Group Support System facilitation, and is a member of ISCAR.

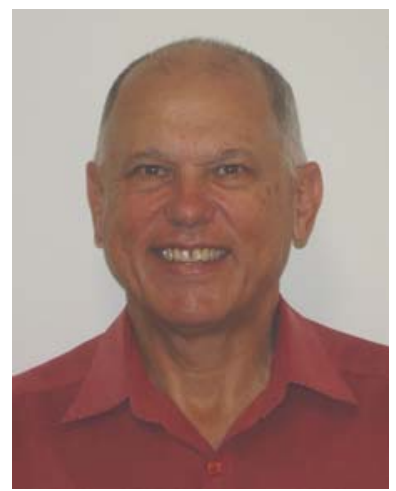

Greg Whymark is Associate Professor in Information Systems at the Faculty of Business and Informatics at Central Queensland University (CQU), Rockhampton, Queensland, Australia. He is head of the Group SolutionS Research Group which is interested in how people and technology work together. The group occupies the old Supreme Court building in Rockhampton City, and has two meeting rooms with group support system technology. He earned his BSc from the university of Queensland, MSc from Wollongong University, and $\mathrm{PhD}$ from the University of New South Wales, and has six research students working on aspects of IS management and knowledge management. His research interests include activity theory, knowledge management and management support systems. 